\title{
MULTI-AGENT SIMULATION FOR SELF-HEALING MECHANISMS OF DAMAGED GEOTECHNICAL STRUCTURES
}

\author{
Darya Filatova \\ Belarusian State University of Informatics and Radioelectronics, Minsk, BELARUS
}

\begin{abstract}
The paper is devoted to the task of multi-agent modeling of self-healing mechanisms for the damaged surface of an abstract geotechnical structure using biotechnology. We consider two-component self-healing mechanism. The first one is presented as a dynamic stochastic model of the aggregated behavior of agents. The second one is described by the "game-of-life" principle. The principals of numerical modeling of both mechanisms are discussed and illustrated by different scenarios.
\end{abstract}

Keywords: multi-agent simulation, Gaussian process, self-healing mechanism, geotechnical structures, biotechnology

\section{МНОГОАГЕНТНОЕ МОДЕЛИРОВАНИЕ МЕХАНИЗМОВ САМОВОССТАНОВЛЕНИЯ ПОВРЕЖДЕННЫХ ГЕОТЕХНИЧЕСКИХ СРЕД}

\author{
Дарья Филатова \\ Белорусский государственный университет информатики и радиоэлектроники, г. Минск, БЕЛАРУСЬ
}

\begin{abstract}
Аннотация: Работа посвещена задаче многоагентного моделирования механизмов самовосстановления поврежденной поверхности некоторой абстрактной геотехнической среды с использованием агломерации бактерии. В качестве механизма предложено использование динамической стохастической модели агрегированного поведения агентов и модели передачи сигнала по принципу игры «жизнь». Представлены алгоритмы численного моделирования разработанных механизмов, а так же результаты их работы для разных сценириев.
\end{abstract}

Ключевые слова: многоагентное моделирование, гауссовский процесс, механизм самовосстановления, геотехнические структуры, биотехнология

\section{INTRODUCTION}

It is well-known, that concrete, being the most world common building materials, as all composite materials, despite its strength, collapses over time. Therefore, the proper engineering and maintenance as well as enhance the durability and serviceability of technical structures become crucial conditions. Under external environmental uncertainty, constructions' reliability still is one of the most important factors during all stages of project development. Lately, the conception of self-healing materials in construction attracts special attention. Named Materials for Life (M4L) and inspired by self-regeneration properties and sustainable development of biological organisms and systems these last find applications in buildings foundations, selected types of cement, grouts and concrete, asphalt and many other geo-environmental and geotechnical structures [1].

Motivated by reliability from one side and by substantial savings maintenance costs of geostructures, the first significant achievements were made in the development of composite materials by adding stabilizing bio-chemical agents to concrete or asphalt. In simple way the self-healing mechanism can be explained as follows [2].

To improve the autogenous healing property of 
concrete, some encapsulated healing agents (usually bacteria) are added to the composite [1-3]. Crack formation and interaction with the external environment instigate metabolic activities of agents and, in consequence, the production of limestone clogging the cracks. The feasibility of this solution was checked in different ways: the influence of capsules' size, the influence of nutrition, dosage etc. [3]. Despite the progress made in this field, there are many nonsolved problems concerning self-healing mechanisms of named composites. One of them relates to the complex environmental behavior of living organisms' agglomerates and has to be also taken into account by biotechnology.

Biotechnology aims to use biological systems to make or modify products or processes for specific purposes of medicine, food production, agriculture, or mentioned engineering problems. Taking into account the complexity of biotechnological processes related to bioengineering, biomedical and molecular engineering, or biomanufacturing, one can expect that integrated multiple biological experiments, as a method of new technology development, are expensive and difficult to conduct. Hence, mathematical modeling and computer simulation via a welldefined set of assumptions can be performed to conduct desired experiments and, in a consequence, to test alternative hypotheses, theories, technologies, production and exploitation methods, etc. The quality of the modeling and the simulation depends on the model selection. This last one can be achieved by different approaches. Analyzing the tendencies of the selection of the mathematic models for the tasks of image and sequences recognition, in signal processing, in biomass dynamic prediction or epidemic spread (where signals contain white, rose or black noises or mixed noises) one can note that due to various heterogeneities the stochastic models give "better" and "richer" results than deterministic ones. It becomes particularly evident when the contact network is analyzed. Contact processes are assumed to be Poisson, Marcovian or non-Marcovian (see [6], [7] - pair approximation model, [8] - [10] - message passing model, or [11] - edge based model). However, to study the propagation mechanisms and dynamics of considered phenomenon, the models have also to reflect complex correlation structures (self-similarity, short-range or longrange dependences, stationarity or nonstationarity) [12]. Thus, due to the complexity of mathematical backgrounds the practical usage of these models is still limited [13].

The goal of this work is the development of a model of self-healing mechanism such that it could serve for the expansion of biotechnology. Since, in general, the technology is based on the metabolic activity of biomass, we will focus our attention on the description of its activity with respect to the single elements as independent agents.

The rest of this paper is organized in the following manner. In Section 2, we propose two models that reflect an individual and aggregated behavior of the agents. For both models, the simulation algorithms are discussed in Section 3. The special attention is focused on the advantages of the mixed fractional Brownian motion application for the transition mechanism. Section 4 contains some illustrations and recommendations on the methodology application and its further development.

\section{THE MODELS OF HEALING MECHANISM}

By the self-healing mechanism, we mean the transition of a bacterium from a state of hibernation (for example, interaction with the environment arising from damage) to a state of metabolic activity in which the bacterium produces a substance that allows filling the crack $^{1}$. The mechanism stops working at the moment of exhaustion of nutrients, as a result of which the bacterium goes into a state of hibernation. Bac-

\footnotetext{
${ }^{1}$ The ideas of this methodology were discussed by the author of this paper in the presentation "Mixed fractional Brownian motion: some perspectives of mathematical modeling for biotechnology" on NANOMED/11th ITMED 2018, Manchester, UK, 26-28 June 2018.
} 
teria transmit signals to each other determining the behavior. We introduce a model of this mechanism, considering two problems, namely: the transition from state to state (dynamic mod$e l$ ) for aggregated behavior and the principle of transmitting alerts about environmental changes of one bacterium (message-passing model).

\subsection{The aggregated behavior model}

Let $N=\{1,2, \ldots, n\}$ denote a universe of encapsulated bacteria (we will call them agents) belonging to the same population. For the simplicity, we suppose that vital dynamics of the population is negligible and that with respect to a certain environmental conditions each agent can stay in one of three states, namely [14]:

- dormancy (the state of those who have the potential and feed for the physiological activity, but not activated yet);

- metabolic activity (the state of those who have been activated by exogenous factors);

- hibernation (the state of those who have been isolated due to lack of the feed or those who have used all the feed and as a consequence were forced to stop the physiological activity).

This subdivision gives three classes of agents according to their activity status. At some moment of time $t, \quad t \in\left[t_{0}, t_{1}\right], \quad S(t), \quad I(t)$, and $R(t)$ represent the cardinalities of dormant, active, and hibernated classes correspondingly. The total population is

$$
\forall t \quad S(t)+I(t)+R(t) \equiv n,
$$

where $S(t) \geq 0, \quad I(t) \geq 0, \quad R(t) \geq 0$.

It is proved that bacteria actively exchange some kinds of chemical signals, coordinating their co-existence. The limited volume of nutrition does not allow on the unlimited growth of the encapsulated population. Moreover, when a lack of nutrition occurs, the agent secretes an appropriate substance, which allows the neighborhood to prepare for the transition to hunger and quickly adjust their metabolic processes.
Following to the ideas of [13], we allow all possible transitions between the states as it shown in Fig.1. Since at any time moment $t$ for each agent, there exist the possibilities of the metabolic changing, there also exist the switching intensities, which depend on individual physiological parameters and on other exogenous factors concerning the population.

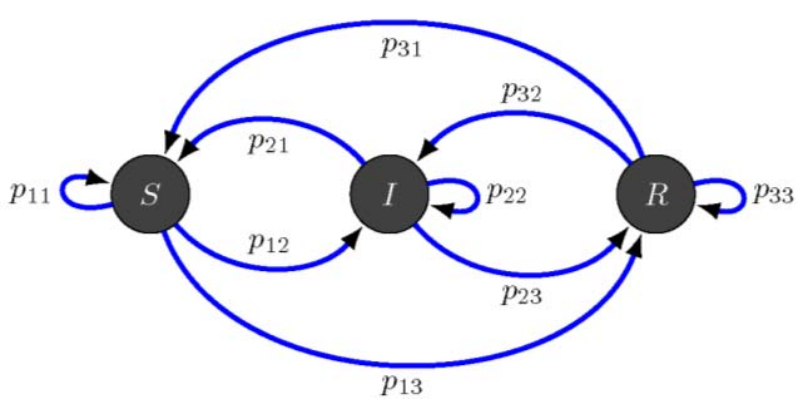

Figure 1. Three-state propagation mechanism ( $S$-dormancy, I - metabolic activity, $R$ - hibernation, $p_{j k}(t), \quad j, k \in\{1,2,3\}$

- the transition intensities).

Moreover, the passage of an agent from state to state occurs on the one hand due to contacts among individuals, on the other due to timevarying exogenous and endogenous factors which cannot be discovered or measured. Therefore, it is possible to assume that these intensities are randomly time-varying, we denote them as $p_{j k}(t) \quad\left(p_{j k} \geq 0, \quad \forall j \quad 0<\sum_{k} p_{j k} \leq 1\right.$, $\left.j, k \in\{1,2,3\}, t \in\left[t_{0}, t_{1}\right]\right)$. Choosing values of the intensities one can get different classical deterministic compartmental models. That is to say if $p_{13}=p_{31}=p_{23}=p_{32}=0$, then one get a well-known in biology "SI"-model, if $p_{13}=p_{21}=p_{32}=0$, then it becomes a "SIRS"model, and etc. (see e.g. [15]).

Without loss of generality, we limit our considerations and put $p_{21}=p_{32}=0$. Moreover, we allow the time-varying stochastic state-to-state transition. Taking into account all the aforesaid, the dynamical model of the spread of the chemical signals, corresponding to the tree-state propagation mechanism (see Fig. 2), takes a form of the following system: 


$$
\left\{\begin{aligned}
\frac{d S(t)}{d t}= & -x_{1}(t) S(t) I(t)+x_{3}(t) R(t) \\
& -x_{4}(t) S(t), \\
\frac{d I(t)}{d t}= & x_{1}(t) S(t) I(t)-x_{2}(t) I(t), \\
\frac{d R(t)}{d t}= & x_{2}(t) I(t)-x_{3}(t) R(t) \\
& +x_{4}(t) S(t),
\end{aligned}\right.
$$

where $x_{1}(t), x_{2}(t), x_{3}(t)$, and $x_{4}(t)$ are the transition rates between states such that $x_{1}$ stands for the transition from the state " $S$ " to the state " $I$ ", $x_{2}$ - from " $I$ " to " $R$ ", $x_{3}-$ from " $R$ " to " $S$ ", and $x_{4}-$ from " $S$ " to " $R$ "; $S\left(t_{0}\right)=s_{0}, \quad I\left(t_{0}\right)=i_{0}$, and $R\left(t_{0}\right)=r_{0}$. The equilibrium of the system (1) means the loose of the self-healing ability of the structure.

Let us comment the parameters of (1). Firstly, these parameters should be smooth enough in order to fulfill the conditions for the existence and uniqueness of the solution.

Secondly, if the time-varying parameters are deterministic, the model (1) displays "mean" behavior. Unlikely, all microorganisms will have the same reactions and, therefore, the same ability to transmit and/or to receive. To reflect the stochastic nature of phenomenon, the transitions rates should be driven by some continuous stochastic processes. Taking into account the ideas of [16] for all $i$ one can put the parameters as

$$
\tilde{x}_{i}(t)=\left(\tilde{x}_{i 0}^{1-m_{i}}-a_{i}\left(m_{i}-1\right) \tilde{B}_{i}(t)\right)^{\frac{1}{\left(1-m_{i}\right)}},
$$

where $\tilde{x}_{i}\left(t_{0}\right)=x_{i 0}$ is the initial value, $a_{i}$ and $m_{i}$ are calibration parameters, $\tilde{B}_{i}(t)$ is some continuous stochastic process, defined as in [17] such that $B_{i}\left(t_{0}\right)=b_{i 0}(i=1, \ldots, 4)$. It seems natural to substitute the parameters (2) into (1) and to get the dynamics of (1), however, the theoretical properties and global behavior of this model are hardly possible to study. The alternative usage of (2) is the application of multiagent modeling, i.e. the transition rates are unique for each agent, the evolution of these rates follows (2), the "global" behavior of (1) is estimated with respect to the cardinal numbers of each class.

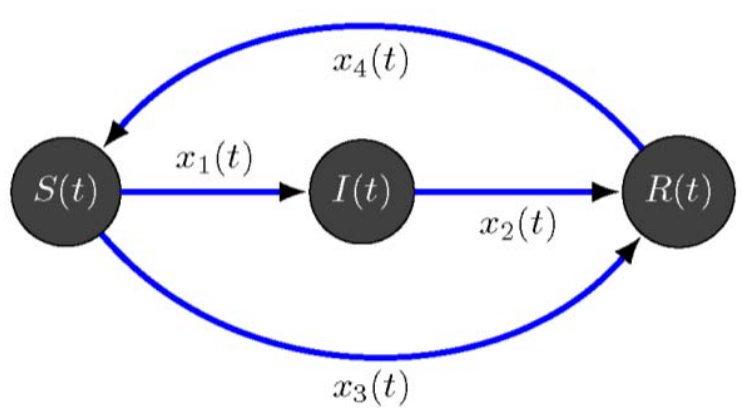

Figure 2. Dynamics of three-state propagation mechanism for the spread of the chemical signals $(S(t)$-dormancy, $I(t)-$ metabolic activity, $R(t)$ - hibernation, $x_{i}(t), i=1, \ldots, 4$ the signal transition rates).

\subsection{The message-passing model.}

Now following the same reasoning as in [18], we suppose that the universe of $N$ agents is an two-dimensional orthogonal grid (it can be easy compared with the damaged surface of an abstract geotechnical structure). Each agent is associated with one square cell of this grid and could interact with its eight neighbors (Moore's model, see Figure 3).

\begin{tabular}{|c|c|c|}
\hline NW & N & NE \\
\hline W & C & E \\
\hline SW & S & SE \\
\hline
\end{tabular}

Figure 3. Moore neighborhood

( $C$-active agent who transmits the signal in the directions $N$ - north, $E$ - east, $S$ - south, $W$-west, $N W$ - north-west, NE - north-east, $S W$ - south-west and SE - south-east). 
Each agent can be dormant, metabolically active, or hibernated forming so-called "configuration" at instant of time $\tau, \tau \in\left[t_{0}, t_{1}\right]$. Each agent has its own endogenous characteristics, which allow it to send and receive signals as well as make the transitions from state to state. At the initial moment $t_{0}$ say $n_{0}$ agents $\left(n_{0}<<n\right.$ ) are randomly activated (it can be considered as an epicenter of the crack on the surface of the geotechnical structure), the rest stay dormant. This configuration leads to a new one at instant of time $\tau+\Delta\left(\Delta>0, \tau+\Delta \in\left[t_{0}, t_{1}\right]\right)$ according to the set of the following rules:

(i) the active agent transmits a signal to the nearest neighbors by Moore scheme with time-varying intensity,

(ii) if the signal is received, the neighbor becomes (with some probability) metabolically active (each agent is characterized by own threshold value for the signal acceptance);

(iii) if the metabolically active agent has two active-neighbor agents at the time $\tau$, then it remains in its state at the time $\tau+\Delta$;

(iv) if the metabolically active agent has less than two active neighbors or more than three, its goes into the hibernation state;

(v) if at some instant in time none of the agents changes state, a universe of agents has the equilibrium, indicating the loss of the ability to self-healing.

\section{SIMULATION ALGORITHM AND SOME RELATED QUESTIONS}

\subsection{The transition rates as the sample paths of the stochastic processes.}

Let $\left(W_{t}\right)_{t \in \mathbb{R}_{+}}$and $\left(W_{t}^{H}\right)_{t \in \mathbb{R}_{+}}$be two independent stochastic processes (say a Brownian motion $(\mathrm{Bm})$ and a fractional Brownian motion (fBm) of Hurst parameter $H \in(0,1)$ ) defined on the same probability space $(\Omega, F, \mathbb{P})$. A process

$$
B^{H}=B^{H}\left(b_{1}, b_{2}\right)=b_{1} W_{t}+b_{2} W_{t}^{H}
$$

is called mixed fractional Brownian motion $(\mathrm{mfBm})$ of parameters $b_{1}, b_{2}\left(b_{1}\right.$ and $b_{2}$ are two real constants such that $\left.\left(b_{1}, b_{2}\right) \neq(0,0)\right)$. The generalized properties of this process were studied and presented in [19, 21, 22]. In our case, we name among others the following properties:

- $B^{H}$ is a centered Gaussian process and $B_{0}^{H}=0$ a.s.;

- for any $t, s \in \mathbb{R}_{+}$the covariance function of $B_{t}^{H}$ and $B_{s}^{H}$ is given by

$$
\begin{aligned}
\operatorname{Cov}(t, s) & =\frac{1}{2} b_{1}^{2}(t+s-|t-s|) \\
& +\frac{1}{2} b_{2}^{2}\left(t^{2 H}+s^{2 H}-|t-s|^{2 H}\right)
\end{aligned}
$$

- for any $\Delta>0$ the increments of $B^{H}$ are stationary and mixed-self-similar

$$
\left\{B_{\Delta t}^{H}\left(b_{1}, b_{2}\right)\right\}^{D}=\left\{B_{t}^{H}\left(b_{1} \Delta^{\frac{1}{2}}, b_{2} \Delta^{H}\right)\right\},
$$

where $=$ means "to have the same law";

- the increments of $B^{H}$ are positively correlated if $\frac{1}{2}<H<1$ (long-range dependence), uncorrelated if $H=\frac{1}{2}$ and negatively correlated if $0<H<\frac{1}{2}$ (short-range dependence).

The sample paths of (3) can be simulated by different methods. We refer to the methodology developed by [20] for the fBm sample paths simulation. This method, based on the fast Fourier transform of the covariance function of the process allows on the multiple simulations of the uncorrelated sample paths of $\mathrm{fBm}$. Moreover, the paper [20] contains the detailed description of the simulation algorithm, therefore we omit it here. The example of several sample paths of (3) for different values of Hurst parameters and $b_{1}=b_{2}=1$ are listed on Figure 4 . As it 
is possible to notice, the $\mathrm{mfBm}$ sample paths give the characteristic mixed-colored noise that is the hallmark of this process.
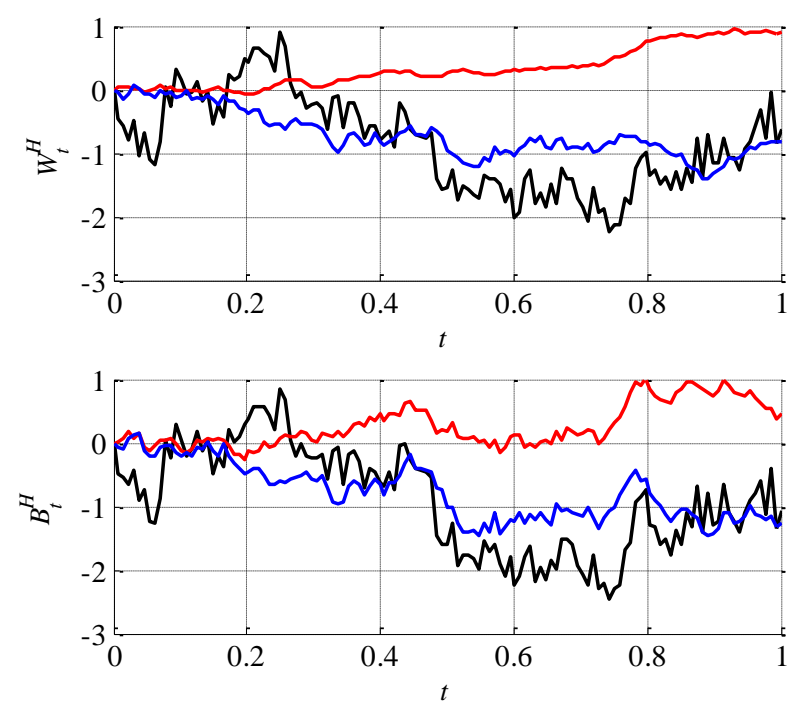

Figure 4. The sample paths of the $\mathrm{Bm}$ and $\mathrm{fBm}$ $\left(W_{t}^{H}\right)$ and the $\mathrm{mfBm}\left(\mathrm{B}_{t}^{H}\right)$ for different values of

Hurst parameter ( $H=0.25$ - red trajectory, $H=0.50$ - blue trajectory, $H=0.75$-black trajectory).

Further, replacing the process $\tilde{B}$ in (2) by the process (3) for $t \in\left[t_{0}, t_{1}\right]$

$$
x(t)=\left(x_{0}^{1-m}-a(m-1) B^{H}(t)\right)^{\frac{1}{(1-m)}},
$$

fixing the initial value $x_{i 0}=0.5$, and taking different values of the scaling parameters $a$ and $m$, we conclude as follows on the behavior of the stochastic process driven by (6). Several examples of the sample paths are presented on Figure 5 and Figure 6.

The mean value of the process (6) oscillates around the initial value (in this case it is 0.5), the variation on the scaling parameters is a convenient way to change the square-mean behavior of the transmission functions between 0 and 1. Therefore, the each agent transmits an activation signal with random intensity such that it can or can not be strong enough to activate neighbors.
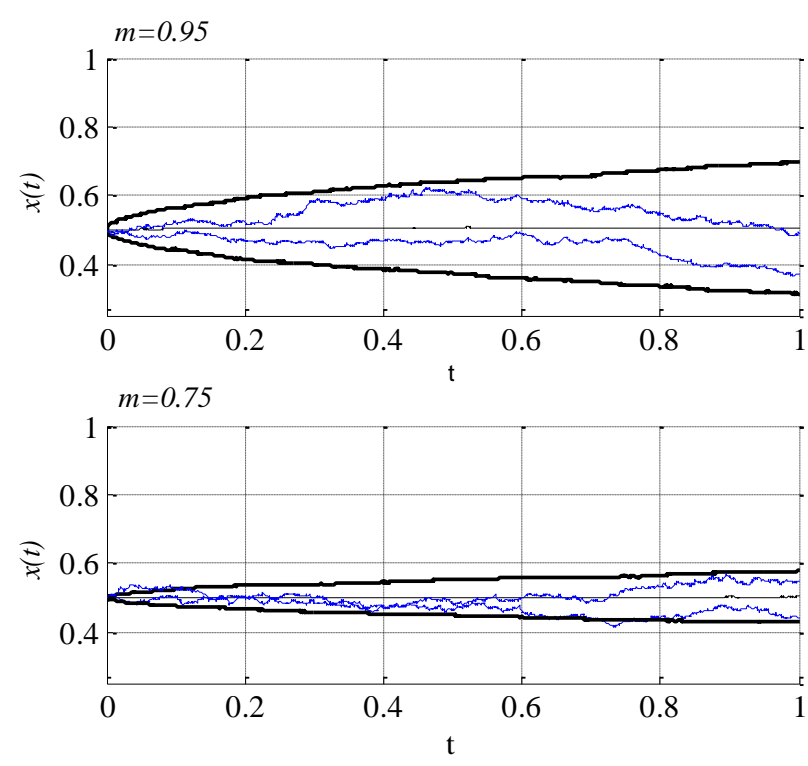

Figure 5. The sample paths of (6) and the confidential interval for $H=0.75$ and $a=0.125$.
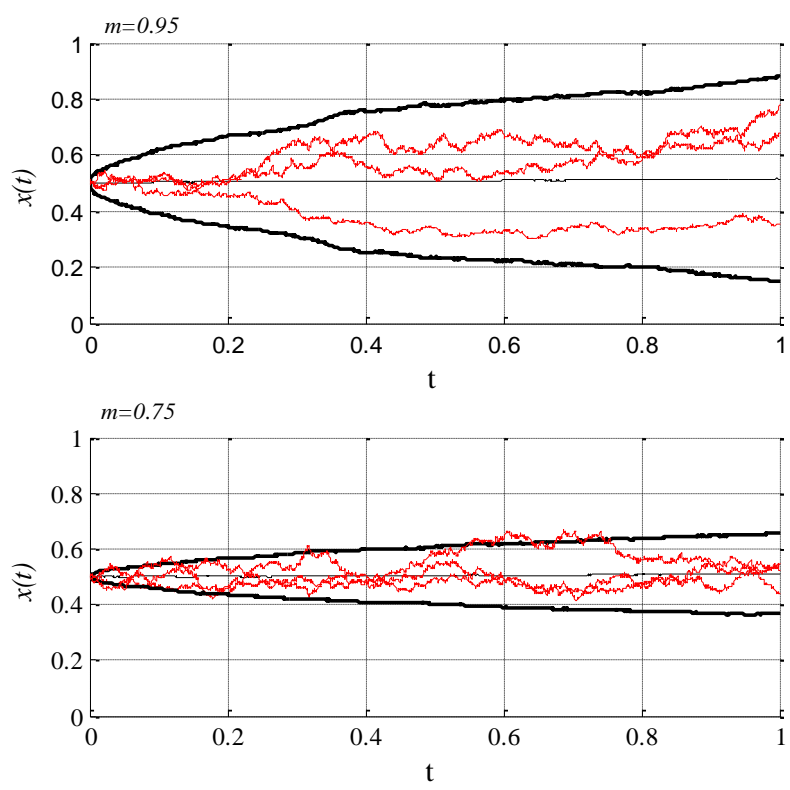

Figure 6. The sample paths of (6) and the confidential interval for $H=0.75$ and $a=0.250$.

\subsection{The simulation algorithm for self-healing mechanism.}

To illustrate the work of the self-healing mechanism, the following algorithm based on the multi-agent simulation method is proposed, namely: 


\section{Initialization - general settings of the artificial environment}

- set the initial grid $M \times M$ and get the number of the agents $n=M^{2}$, initially each cell is associated with one non-activated anent;

- set the evolution time period $\left[t_{0}, t_{1}\right]$;

- define the $m$-stages equidistant discretization of the evolution time period $\left[t_{0}, t_{1}\right]$, such that $\quad \tau_{j}=\tau_{j-1}+\Delta, \quad \Delta=\frac{t_{1}-t_{0}}{m}, \quad \tau_{0}=t_{0}$, $j=1,2, \ldots, m$;

- the initial cardinalities of groups: $I\left(\tau_{0}\right)=n_{0}$, $S\left(\tau_{0}\right)=n-n_{0}$, and $R\left(\tau_{0}\right)=0$;

- the "mean" ability of the transmitted signal acceptance $\beta$,

- the initial values of transitions rates $x_{i 0}$, values of parameters $a_{i}$ and $m_{i}, i \in\{1,2,3,4\}$.

\section{Initialization - agent's and transmission characteristics:}

- for each agent generate the set of the $\mathrm{mfBm}$ sample paths with the same values of $b_{1}, b_{2}$ and $H$ using the $m$-stages equidistant discretization of the evolution time period,

- for each agent calculate the transmission characteristics (6) with respect to the set of the $\mathrm{mfBm}$ sample paths.

\section{Processing - step evolution over time line $\left[t_{0}, t_{1}\right]$ :}

- activate the agents who will transmit the signal (select circle in the center of the grid with a radius of $r<<M$ cells and consider the agents inside this circle as the activated one we will call it as Protocol I - or activate the agents in randomly selected cells - we will call it as Protocol II);

- define the rules for the Moore neighborhood for the eight nearest neighbors (see Fig. 3);

- for each step of the evolution iterate over all cells in grid the spread of activation signal;

- if the agent is active, check the activity of the neighbors according to the rules (i) - (iv) and update the status of the agent;
- count the cardinality number of each group, check the rule $(\mathrm{v})$, if the rule (v) is fulfilled stop the evolution.

\section{Aggregating behavior:}

- complete the parametric identification of aggregate model (1) and its analysis.

\section{SIMULATION RESULTS}

We run several numerical experiments under Protocol I and Protocol II excluding the last step of the algorithm from the simulations. The interested reader can find all the details for the identification of the aggregated behavior and to get qualitative characteristics of the system (1) (for the details see [23]). In this work, the general settings of the artificial environment are the following, namely: $M=100, t_{0}=0, t_{1}=1$, $m=500, r=4$ (for Protocol I), $n_{0}=50$ (for Protocol II), $x_{10}=0.5, x_{20}=0.4, x_{30}=0.55$, $x_{40}=0.45 ; \quad H_{i}=0.75, \quad a_{i}=0.025 \quad$ and $m_{i}=0.85, i \in\{1,2,3,4\} ; b_{1}=0.7, b_{2}=0.3$; the update rules for the Moore neighborhood are given in matrix form

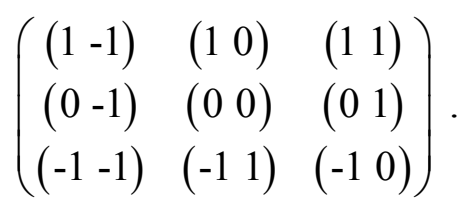

The results of simulations are listed on Fig. 7 10 (blue, green, or red color refers to the dormant, metabolically active, or hibernated agent correspondently).

As one can see the initial placement of the active agents and relation between the mean ability of the transmitted signal acceptance and the initial values of transition rates have the crucial role in self-healing dynamics (compare Figure 7 with Figure 9 and Figure 8 with Figure 10). That is to say, for $\beta=x_{01}=0.5$ the equilibrium is reached faster if the activated agents are randomly distributed on the damaged surface. 
$t=0$

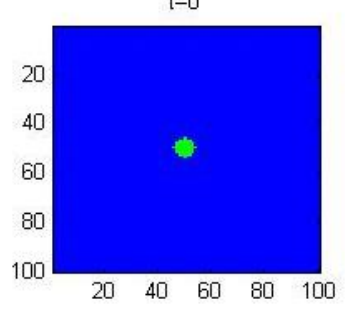

$t=100$

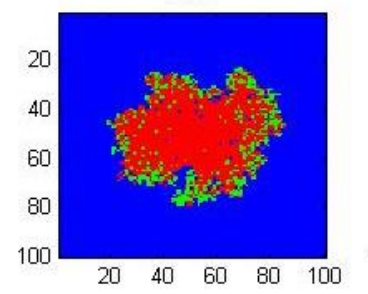

Figure 7. Protocol I $(\beta=0.5)$.

$t=0$

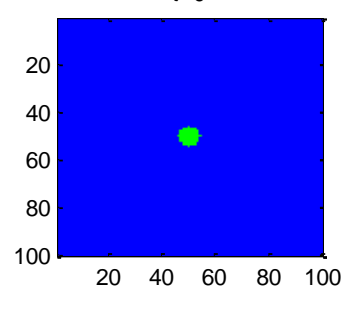

$t=100$

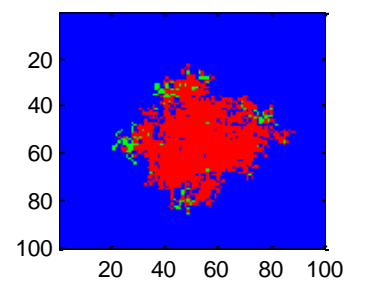

Figure 8. Protocol I $(\beta=0.1)$.

Moreover, the "repaired" surfaces can be compared by quantities of hibernated and dormant agents. In the case for $\beta<x_{01}$ the equilibrium is reached faster for the case when agents are concentratedly placed. This means that the transmission of the activation signal stops faster too (compare all the figures). Therefore, varying the parameters of the simulation model one can study different phenomena of the signals' transmissions.
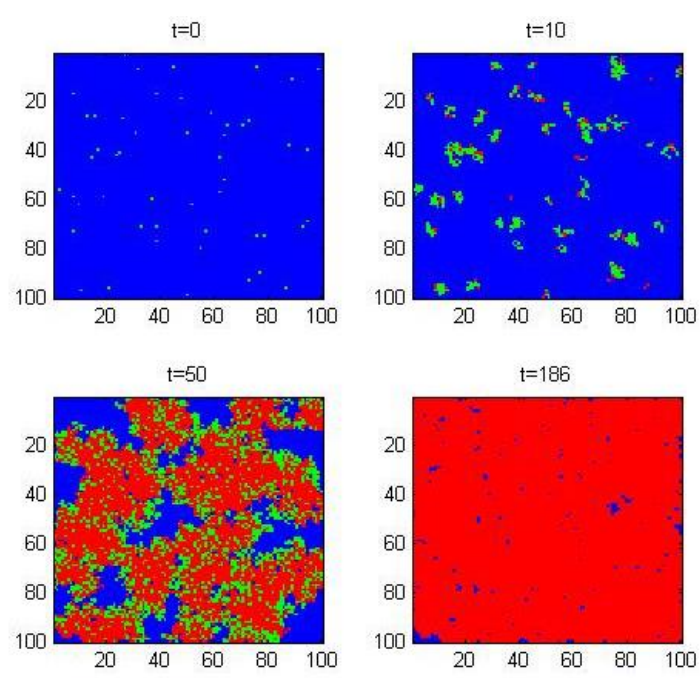

Figure 9. Protocol II $(\beta=0.5)$.
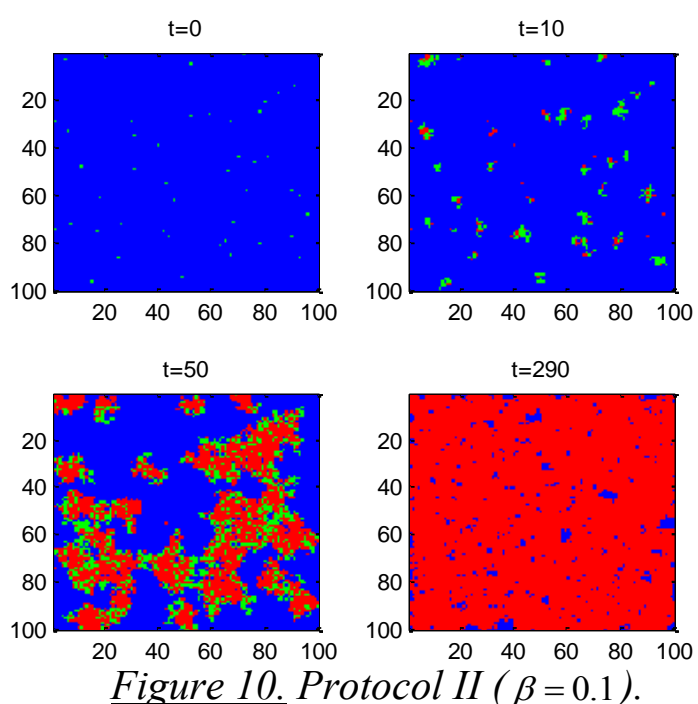

\section{CONCLUSIONS}

The self-healing mechanisms for the damaged surface of an abstract geotechnical structure using biotechnology attract much attention of many scientists from different fields. Multiagent modeling can help to solve numerous problems arising during new technology development. Proposed in this paper the twocomponent model of self-healing mechanism allows on the imitation of one or several cracks on a surface and on the estimation of life cycle of the material. In further investigation the 3D model of cracks as well as the parameters of the biologically active elements of the composites will be considered. 


\section{REFERENCES}

1. Gardner D., Lark R., Tony J., Davies R. A survey on problems encountered in current concrete construction and the potential benefits of self-healing cementitious materials. // Case Studies in Construction Materials, 2018, Volume 8, pp. 238-247.

2. Wiktor V., Jonkers H. M. Quantification of crack-healing in novel bacteria-based self-healing concrete. // Cement and Concrete Composites, 2011, Volume 33 (7), pp. 763-770.

3. Hilloulin B., Hilloulin D., Grondin F., Loukili A., De Belie N., Mechanical regains due to self-healing in cementitious materials: Experimental measurements and micro-mechanical model. // Cement and Concrete Research, 2016, Volume 80, pp. 21-32.

4. Ahn T. , Kim H., Ryou J. New SurfaceTreatment Technique of Concrete Structures Using Crack Repair Stick with Healing Ingredients. // Materials, 2016, No. 9(8), pp. 654.

5. Huang H., Ye G., Shui Z., Feasibility of self-healing in cementitious materials - By using capsules or a vascular system? // Construction and Building Materials, 2014, Volume 63, pp. 108-118.

6. Sharkey K.J. Deterministic epidemiological models at the individual level. // Journal of Mathematical Biology, 2008, Volume 57, Issue 3, pp. 311-331.

7. Kiss I. Z., Rost G., Vizi Z. Generalization of pairwise models to non-markovian epidemics on networks. // Physical Review Letters, 2015, Volume 115 (7), pp. 078701.

8. Karrer B., Newman M.E.J. Message passing approach for general epidemic models. // Physical Review E, 2010, Volume 82(1), pp. 016101.

9. Simon P., Taylor M., Kiss I., Exact epidemic models on graphs using graphautomorphism driven. // Journal of Mathematical Biology, 2011, Volume 62(4), pp. 479-508.
10. Wilkinson R.R., Ball F.G., Sharkey K.J. The relationships between message passing, pairwise, kermack-mckendrick and stochastic SIR epidemic models. // Journal of Mathematical Biology, 2017, Volume 75, Issue 6, pp. 1563-1590.

11. Miller J.C. Spread of infectious disease through clustered populations. // Journal of the Royal Society Interface, 2009, Volume 6(41), pp. 1121-1134.

12. Angstmann C., Henry B., McGann A. A fractional-order infectivity sir model. // Physica A: Statistical Mechanics and its Applications, 2018, Volume 452, pp. 86-93.

13. Lu J., Yu X., Chen G., Yu W. Complex Systems and Networks: Dynamics, Controls and Applications. Springer-Verlag Berlin Heidelberg, 2016.

14. Evdokimova N.V., Tchernenkaya T.V. Persister Microbial Cells: a Novel View on the Old Problem. // Clinical Microbiology and Antimicrobial Chemotherapy, 2013, Volume 15(3), pp. 192-197.

15. Edelstein-Keshet L. Mathematical models in biology. SIAM, 2005.

16. Galleani L. Time-Frequency Characterization of Stochastic Differential Equations. In Rodino L., Wong M., Zhu H. (Eds.) Pseudo-Differential Operators: Analysis, Applications and Computations. Operator Theory: Advances and Applications, 2011, Volume 213, Springer, Basel, pp. 265-274.

17. Samorodnitsky G., Taqqu M.S. Stable non-Gaussian random processes. Chapman \& Hall, 1994.

18. Chu G., Karen K.E., Yorke-Smith N., Constraint Programming to Solve Maximal Density Still Life. In: Adamatzky A. (Ed.) Game of Life Cellular Automata, Springer London, pp. 167-175, 2010.

19. El-Nouty C. The fractional mixed fractional Brownian motion. // Statistics \& Probability Letters, 2003, No. 65(2), pp. 111-120.

20. Stoev S., Taqqu M.S. Simulation methods for linear fractional stable motion and FARIMA using the fast Fourier transform. // Fractals, 2004, No. 12(1), pp. 95-121. 
21. El-Nouty C., Journé J-L. Upper classes of the bifractional Brownian motion. // Studia Sci. Math. Hungar, 2011, Volume 48, pp. 371-407.

22. El-Nouty C. On approximately stationary Gaussian processes. // International Journal for Computational Civil and Structural Engineering, 2015, Volume 11, pp. 15-26.

23. Filatova D.V., Baratgin J. Multi-agent social choice model and some related questions. // 11th International Conference on Human System Interaction, 2018, pp. 425431.

24. Filatova D., Bourgeois-Gironde S., Baratgin J., Jamet F., Shao J. Cycles of maximin and utilitarian policies under the veil of ignorance. // Mind and Society, 2016, No. 15(1), pp. 105-116.

Филатова Дарья, профессор, доктор физикоматематических наук, кафедра информатики факультета компьютерных систем и сетей Белорусского государственного университета информатики и радиоэлектроники; Ассоциированный член Лаборатории человеческого и искусственного познания Практической школы высших исследований; 220013, Республика Беларусь, г. Минск, ул. П. Бровки, д. 6;

E-mail: filatova@bsuir.by;

orcid.org/0000-0001-9434-7993.

Darya Filatova, Professor, Dr.hab., Informatics Department, Faculty of Computer Systems and Networks, Belarusian State University of Informatics and Radioelectronics, Minsk, Belarus and associated member of CHART EPHE, Paris, France; BSUIR, Gikalo 9, 220005 Minsk, Belarus; E-mail: filatova@bsuir.by. 